\title{
RAZÓN Y RAZONES DEL VALOR: LA AXIOLOGIA DE LA ESCUELA DE OXFORD
}

La Escuela de Oxford es en este momento una de las más influyentes en el campo de la filosofía. Sus contribuciones a la Ética y la Axiología pretenden dar una explicación lógica de la moral y del valor. Se oponen en este sentido al positivismo lógico radical que mantiene que los valores están más allá de los linderos de la lógica. Sin embargo -ésta es la tesis de la exposición siguiente-, las lógicas aducidas por estas obras son construcciones ad hoc sin conexión con ningún sistema lógico y por eso no ameritan el nombre de lógica. Son análisis semánticos del uso del lenguaje ordinario en el discurso del valor.

Me propongo criticar estas doctrinas a la luz de la lógica del valor o sea de la axiología formal.

La escuela de Oxford puede llamarse la expansión axio-lingüística de las enseñanzas de Wittgenstein, del mismo modo que la doctrina de Hall es su expansión axio-ontológica. ${ }^{1}$ Según Wittgenstein, el filósofo es el terapeuta de la enfermedad de la sistematización, es decir, de la sistematización filosófica analítica, no de la científica sịntética. Suponiendo que la sistematización filosófica sea una enfermedad lingǘstica - y la propia axiología formal no se encuentra muy lejos de esta posición-, la receta que ofrece Wittgenstein es "Retroceder a la locución ordinaria", mientras que la de la axiología formal es "Avanzar hacia la precisión crentifica". En ia jerarquía kantiana de la conceptualización, Wittgenstein invita al filósofo, que se encuentra en el nivel de la definición analítica, a deslizarse en retroceso hacia la descripción primitiva y la aporética, mientras que la axiología formal le pide que dé un salto adelante hacia la definición sintética y la axiomática. Todo lo que el filósofo debe hacer, según Wittgenstein, es "representar perspicuamente" ("übersichtlich darstellen") cómo se usa la palabra o frase que le interesa en los diversos juegos de lenguaje en que ocurre. El filósofo se convierte así en un jugador y la filosofía en un juego: un juego con usos de palabras. En vez de orientar al hombre en su perplejidad, como es su misión socrático-platónica, el filósofo se convierte en el colmo de la perplejidad. Se divierte jugando con la condición humana. No es sorprendente, pues, que en este proceso la perplejidad del hombre

I What is Value? An Essay in Philosophical Analysis, Londres, Nueva York, 1952; "Practical Reason(s) and the Deadlock in Ethics", Mind, 64, págs. 319-332 (1955). Cf. el artículo del autor, "La simbolización del Valor", Did́noia, 1969. 
ordinario llegue a equipararse con la del filósofo, como tan claramente lo demuestran los últimos escritos de Wittgenstein.2

Mientras que, de tal suerte, la tarea positiva del filósofo, según esta escuela, es llevar la anotación en los juegos de lenguaje, su tarea negativa consiste en mostrar la futilidad y la naturaleza fundamentalmente errónea de cualquier búsqueda de definiciones. Las definiciones, dice Hampshire, han sido el "fuego fatuo" de la teoría del valor. ${ }^{3}$ Su búsqueda se ha apoyado en el supuesto de que podría hallarse una sola fórmula, tal como el principio de la mayor felicidad, de la cual sea posible deducir juicios acerca de lo que es bueno y lo que es correcto. En lugar de ofrecer definiciones, el filósofo debe dedicarse a dar "especímenes" de razones que serían aceptadas como pertinentes en situaciones morales, y a "describir especímenes de conductas a las que son aplicadas... Un tratado de ética informativo - o sobre la ética de una sociedad o persona particular - contendría una acumulación de ejemplos seleccionados para ilustrar las clases de decisiones que se consideran correctas en diversas circunstancias, y las razones que se dan y los argumentos que se usan al concluir que son corrèctas". Así, pues, como señala Hall, ${ }^{4}$ la razón, que en la tradición de la filosofía moral es guia de la conducta humana, es fragmentada por esta escuela en una multitud de razones situacionales. En lugar de Razón Práctica hay una variedad infinita de razones prácticas, cada una de ellas con su propia normatividad peculiar. "La característica distintiva de los juicios prácticos", dice Hampshire, 5 "es que éstos tienen una fuerza prescriptiva o cuasi-prescriptiva como parte de su significado". Lo que se prescribe no es una actitud - la característica de la teoría emotiva-, sino "un curso de acción o un modo de vida". Pues, si examinamos lós usos de los juicios éticos, vemos que todos se centran alrededor de los problemas del agente moral que está tratando de decidir qué hacer en una situación en la que tiene que hacer una elección y luego obrar a base de ella. "El problema moral típico no es el problema de un espectador o un problema de clasificar o describir la conducta, sino un problema de elección y decisión prácticas.". La escuela es incapaz de ver que este problema moral no es el problema ético. La Razón por medio de la cual el ético da cuenta de la razón moral es diferente de las razones por las cuales el agente moral decide, en su situación. Tenemos aquí la confusión de método y contenido que se encuentra tan frecuentemente en la literatura ética. ${ }^{6}$

2 Cf. A. R. Anderson, "Mathematics and the 'Language Game", Review of Metaphysics, XI, págs. $44^{6-458}$ (marzo de 1958).

3 "Fallacies in Moral Philosophy", Mind, 58 , págs. $466-482$ (1949).

4 "Practical Reason (s) and the Deadlock in Ethics", Mind, 64, págs. $319-33^{2}$ (1955).

5 "Fallacies in Moral Philosophy", Mind, 58, págs. $466-482$ (1949).

6 Véase La estructura del valor, del autor, Fondo de Cultura Económica, México, 1959, Introducción y passim. 
La teoría "al detalle" del juicio moral, ve, pues, el carácter moral de uná situación en el proceso de decisión. De tal suerte, como la teoría stevensoniana en la interpretación de Stroll, es una versión lingüísticamente disfrazada de una teoría naturalista. El lenguaje no es sino el signo evidente y "lógicamente" accesible del rasgo de elección-y-decisión de una situación. Aquí reside el significado axiológico más profundo de la concepción wittgensteiniana del lenguaje como un juego: la valoración es un juego de elecciones en situaciones. ${ }^{7}$

Siendo el lenguaje un rasgo de la situación, y considerado su carácter situacional como su rasgo de valor esencial, el lenguaje ejecutorio, es decir, el lenguaje como rasgo constitutivo de una situación, tiene para esta escuela una pertinencia particular para la valoración. Este aspecto de la concepción de Oxford ha sido desarrollada, sobre la base de la obra clásica de Austin, ${ }^{8}$ por varios autores agudos para toda clase de contextos. Hart; ${ }^{9}$ por ejemplo, establece una analogía entre las oraciones ordinarias y el discurso legal. Conceptos como "contrato", "propiedad", "transgresión" y otros similares no son descriptivos en el sentido de ser susceptibles de definición - dando condiciones necesarias y suficientes para la existencia de contratos, propiedad, etc.-, sino que son designados mediante enumeraciones de casos, nunca cerradas, y con amplios y abiertos "etcéteras". Más aún, estos conceptos son derrotables en el sentido de que, incluso donde los elementos normales y fijos de un contrato parecen estar presentes, toda una legión de condiciones "a menos que" (que no haya coacción, que no haya propósitos inmorales, etc.) abren caminos para la posible "derrota" de la existencia de un contrato. A similitud de estos conceptos legales, los conceptos ordinarios de acción y las oraciones como "Esto es tuyo", "Esto es mío", etc., no son usados para describir, ni tampoco emotivamente, sino para atribuir derechos y responsabilidades, y para reclamar derechos, reconocer derechos,

7 Este pensamiento puede ser desarrollado descriptiva y formalmente, ya sea lógicamente o matemáticamente. Cf. Davidson, Suppes, Outline of a Formal Theory of Value, I, Stanford, California, 1954, y Decision Making, Stanford, California, 1957; R. B. Braithwaite, Theory of Games as a Tool for the Moral Philosopher, Cambridge, 1955; N. M. Smith, Jr., "A Calculus for Ethics: A Theory of the Structure of Values", Behavioral Science, I, págs. 111-141, 186-211 (1956). Puesto que tal tratamiento "formal" se basa en un concepto analítico o categorial, el de la elección, no es un tratamiento genuinamente sistemático, es decir, sintético o axiomático, del asunto. Aplica a cualidades secundarias un recurso que es aplicable solamente a cualidades primarias. Su posición metodológica es, pues, la de la numerologia pitagórica más bien que la de la fenomenología matemática newtoniana. Véase el articulo del autor citado en la nota 1.

8 "Other Minds", Proc. Arist. Soc., Supp., 20, págs. 148-187 (1946); Logic and Lan. guage, II, Flew, E.G.N., ed., Oxford, 1953. También véanse Philosophical Papers, Oxford, 1961; Sense and Sensibilia, Oxford, 1962; How to Do Things with Words, Oxford, 1962; y Donald Evans, The Logic of Self-Involvement, London, 1963.

จ "The Ascription of Responsability and Rights", Proc. Arist. Soc., 49, págs. 171-194 (1948-1949). También en Logic and Language, Flew, E.G.N., ed., Oxford, $195^{1 .}$ 
etcétera; y todo esto es parte del juzgar en el sentido práctico de decidir. Muchas de estas oraciones pueden ser explicádas sólo en referencia al contexto no-descriptivo de la ley. Por ejemplo, la diferencia entre "Su cuerpo se movió en contacto violento con el de otra persona" y "Él lo hizo" (por ejemplo "Él le pegó a ella") sólo puede explicarse en referencia al uso no-descriptivo de las oraciones, mediante el cual se atribuyen obligaciones o responsabilidades. Obviamente, esta concepción de las oraciones legales se basa más bien en la naturaleza del derecho anglosajón que en la del europeo, y tiene, por tanto, una base un tanto provinciana, tanto geográfica como metodológicamente. En realidad, como lo han demostrado García Máynez ${ }^{10}$ y otros, todas estas normas legales son ejemplificaciones de principios lógica y ontológicamente formales que no difieren, en este respecto, de las leyes científicas. Así, pues, tenemos aquí otro caso de conversión de ejemplificaciones específicas de principios generales en prototipos, más bien que de elaboración de principios: el típico procedimiento de poner el carro delante de los caballos, que es el rasgo distintivo de esta escuela. La ingeniosidad con que sus afiliados llevan a cabo la búsqueda de contextos prototípicos competitivos está en proporción directa con su ingeniosidad para evitar los principios formales genuinos. Margaret Macdonald ${ }^{11}$ propone que los juicios éticos no sean concebidos siguiendo el patrón de los juicios científicos, ni tampoco el de las órdenes o expresiones de actitudes, sino por analogía con, o según el "modelo" de, ciertas clases de frases ceremoniales tales como las del ritual religioso y los procedimientos legales. Cross 12 hace uso de la distinción de Ryle entre "saber cómo" y "saber qué". 13 L. J. Russell ${ }^{14}$ sostiene que los juicios morales deben ser interpretados como propuestas. "Las propuestas pueden ser discutidas, se pueden dar razones en favor y en contra de ellas; pero estas razones son razones para hacer algo, y no razones para aceptar algo como verdadero."

Todas estas propuestas son ejercicios en una nueva "lógica". Ningún tipo tradicional de lógica, sostiene la escuela, es capaz de analizar el carácter situacional o contextual del lenguaje sin forzarlo dentro de una camisa de fuerza que le robaría su significado vital.15 Las palabras de valor, tal como se las utiliza en el discurso ordinario, no pueden ser entendidas por

10 Introducción a la Lógica juridica, México, 1951; Lógica del juicio juridico, México, 1955 .

11 "Ethics and the Ceremonial Use of Language", Philosophical Analysis, M. Black, ed., Ithaca, N. Y., $195^{\circ}$.

12 "The Emotive Theory of Ethics", Proc. Arist. Soc. Suppl. 22, págs. 127-140 (1948). 13 G. Ryle, The Concept of Mind, Londres, 1949, cap. Ir.

14 "Moral Statements as Proposals", Australasian Journal of Psychology and Philosophy, 3o, 1 (1952).

$1 \overline{5}$ Obsérvese la similitud con la "razón vital" de Ortega y Gasset. Pero mientras Ortega y Gasset piensa en la "razón vital" con la impulsividad de un torero, el sabio de Oxford lo hace con la minuciosidad de un disector. 
lenguajes ideales o construcciones lógicas artificiales. El razonamiento ético sigue una lógica sui generis, diferente tanto de la lógica inductiva como de la deductiva. La definición debe ser reemplazada por modelos que reflejen más o menos cada situación posible y expliquen el uso de los términos de valor en ella. Debemos, por decirlo así, aplicar el microscopio a cada situación y examinar cómo se usan los términos de valor en su contexto. Al hacer tal cosa, como indica Ryle, 16 debemos tener cuidado de no confundir dos clases de uso (use y usage). El uso (en el sentido de usage) es materia para el estudio fáctico que debe dejárseles a los autores de diccionarios. El estudio de uso (en el sentido de use) no es asunto de la lingüistica, sino de la lógica, una lógica de un nuevo tipo que implica la concepción pluralista de los juegos de lenguaje. Hace imposible hacer encajar los significados éticos en cualquiera de las clasificaciones existentes, ni siquịera la dicotomía cognoscitiva-emotiva de la escuela emotivista.

Así, pues, si bien la Escuela de Oxford comparte el énfasis prescriptivo de la teoría emotiva, se niega a abandonar la concepción de algún tipo de validez en la inferencia ética. Nos recuerda el hecho de que si ofrecemos afirmaciones fácticas como razones para conclusiones morales y consideramos algunas razones mejores que otras. En el juicio práctico, dice Hampshire, ${ }^{17}$ hay patrones de argumentación "que pueden describirse como más o menos racionales en el sentido de que están gobernados más o menos estrictamente por reglas de pertinencia reconocidas (aunque no necesariamente formuladas)". Así, pues, las situaciones morales, es decir, de decisión, tienen sus razones. La Escuela de Oxford es más racional que la escuela emotiva semi(no-)cognoscitivista, pero menos racional que las escuelas cognoscitivistas. Es, pues, más bien semi-cognoscitivista que semi-no-cognoscitivista; su énfasis cognoscitivista prepondera sobre su énfasis no-cognoscitivista. ${ }^{18}$ Este último reside en su insistencia en la "esterilidad" de las definiciones en la ética, que es una de las cuatro falacias en la filosofía moral según Hampshire; mientras que su énfasis cognoscitivista reside en su reconocimiento de las razones situacionales, siendo la irracionalidad de las situaciones morales otra de las concepciones falaces de la filosofía moral. Pero esta racionalidad no es científica o naturalista - una tercera falacia-, sino sui generis; empero, tiene relaciones con cuestiones de hecho, y negar esto es la cuarta falacia. ${ }^{19}$ Las razones en las situaciones morales son, pues, morales y razones: no son otra cosa sino morales - y en este respecto la escuela desarrolla el punto esencial planteado por G. E. Moore- y no son otra cosa sino

10 “Ordinary Language", Philosophical Review, 62, págs. 167-186 (1953).

17 "Fallacies in Moral Philosophy", Mind, 58, págs. $4^{66-4} 82$ (1949).

18 Véase el artículo del autor, "La filosofía del valor a mediados del siglo xx", Dianoia, $195^{8 .}$

19 Es sorprendente la libertad con que los críticos de la "falacia" naturalista de Moore se apropian el método de éste. 
razones, no son órdenes -más bien orientan que incitan, para decirlo en palabras de Falk_-20 y en este respecto la teoría contradice la teoría emotiva. De tal suerte, aunque la teoría formalista semi-cognoscitiva es más cognoscitiva que la teoría emotiva, no es una teoría cognoscitiva, pues, como hemos visto, si bien reconoce razones, niega la Razón en la axiología. Su "razón" en las situaciones morales es al detalle, no al por mayor. La Razón, presumiblemente, surgiría de la definición abarcadora de todo, que es descartada. La escuela aborda el problema del valor inductiva o empíricamente; busca el valor, como lo ha expresado felizmente Edel, ${ }^{21}$ en las situaciones, del mismo modo que el científico empirista busca especímenes en la naturaleza. Pero no busca la síntesis abarcadora de todo, que produciría una disciplina de la Axiología. Es una axiología más bien linneana que darwiniana, y lo es consciente y militantemente. No hay en la ética un problema fundamental, dice Toulmin. ${ }^{22}$ La creencia de que hay uno es la que ha dado origen al sentimiento de que la filosofía moral no progresa. Hay muchos problemas, y el progreso de la filosofía moral radica en la dilucidación de esos problemas uno por uno.

Aquí tenemos un buen ejemplo de convertir en virtud una supuesta necesidad. Para Toulmin, ${ }^{23}$ un juicio ético es un juicio de que algo constituye una buena razón para obrar de cierta manera. Las razones, insiste él, pueden ser buenas o malas aun si no dan una prueba lógica o científica de lo correcto de las acciones que indican. Fiel al principio axio-empírico de la escuela, Toulmin explora situaciones individuales de decisiones y distingue en ellas varios tipos de "buenas razones", tales como razones para un acto particular bajo un código existente, razones para alterar o mantener un código (por ejemplo, en términos de aminorar el sufrimiento), razones para confiar en un hombre que recomienda reformas, y así por el estilo. Pero Toulmin se niega a reconocer la Razón en la ética; sospecha de las teorías: "Una explicación descriptiva de nuestros conceptos éticos es lo que necesitamos... La Etica tiene que ver con la satisfacción armoniosa de deseos e intereses". Con todo, Toulmin no se coloca más allá de la generalización. "En la mayor parte de las ocasiones es una buena razón para elegir o aprobar un acto el que esté de acuerdo con una máxima de conducta establecida, pues el código moral existente y las instituciones y leyes prevalecientes ofrecen la orientación más confiable en cuanto a qué

20 "Goading and Guiding", Mind, 62, págs. $145^{-171}$ (1953).

21 "Ethical Reasoning", Academic Freedom, Logic, and Religion, White, M., ed., Phi ladelphia, 1953, pág. 134: "En cada segundo número de Mind se anuncian nuevos ha. llazgos".

22 "Is There a Fundamental Problem in Ethics?", Australasian Journal of Psychin. logy and Philosophy, 33, págs. 1-19 (1955).

23 "Knowledge of Right and Wrơng", Proc. Arist. Soc., 5o, págs. 139 sigs. (1949-1950); An Examination of the Place of Reason in Ethics, Cambridge, 1950. 
decisiones serán afortunadas, de la misma manera que los códigos de la práctica corriente en la ingeniería".24 $\mathrm{Si}$ tal práctica es operante, es digna de adopción. A cualquiera que pregunte: ¿Por qué son buenas estas razones?, "yo sólo puedo contestarle preguntando a mi vez: ‘QQué mejores razones podría usted desear?" "25 Mackie replica que a él le gustarían unas razones un poco menos convencionales. ${ }^{26}$

De tal suerte, los rebeldes contra la filosofía terminan como conformistas con la sociedad.

Otros miembros de la rama inglesa de la escuela semi-cognoscitivista comparten con Toulmin la peculiar combinación de originalidad teórica y trivialidad práctica que es señal distintiva de todos los procedimientos analíticos agudos - tan conspicuamente demostrada en la ciencia natural por los alquimistas-, en tanto que la combinación exactamente opuesta, la trivialidad teórica (de los axiomas evidentes en sí mismos) unida con originalidad práctica revolucionaria, es la señal distintiva de todos los procedimientos sintéticos. Las obras más notables de la escuela semi-cognoscitivista, además de la de Toulmin, son la de Hare y la de Nowell-Smith. El libro de Hare ${ }^{27}$ ha sido probablemente el más influyente en la Gran Bretaña durante la última década, quizá porque Hare examinó con mayor claridad que cualquier otro trabajo comparable la relación fundamental de la axiología, o sea la relación entre las propiedades descriptivas (hacedoras de valor) y las propiedades de valor de una cosa. El hecho de que, pese a sus esfuerzos, esta relación permanezca esencialmente oscura, confirma que existe una brecha entre la axiología analítica y la sintética que ningún procedimiento analítico, por agudo que sea, puede cerrar.

Hare se acerca a una teoría imperativa de los juicios de valor, aunque no llega a adoptarla. Según su concepción, los juicios éticos consisten en a) un elemento descriptivo naturalista, b) un elemento prescriptivo análogo, pero no idéntico a un imperativo. Hare insiste en que nunca se pueden inferir conclusiones éticas, como prescriptivas, de indicativas solamente, refutando así por igual la concepción naturalista y la concepción de Moore de que los deberes pueden derivarse de una propiedad no-natural indefinible de bondad poseída por las consecuenciás de los actos.

La palabra mágica de Hare es "recomendar". La finalidad principal de decir que algo es bueno es recomendarlo. La objeción más importante de Hare al naturalismo es que, si identificamos to bueno -ya sea en la esfera de la ética o en la de, por ejempjlo, la estética- con una propiedad

24 Ibid., pág. 223.

25 Ibid.

26 Reseña de "The Place of Reason in Ethics" por E. S. Toulmin, Australasian Journal of Psychology and Philosophy, 29, págs. $14_{4} \cdot 124$ (1950).

27 The Language of Morals, Oxford, 1952. 
fáctica particular, no podremos entonces recomendar nada por tener esa propiedad. Esta objeción, insiste Hare, no tiene nada que ver con la moral en particular, sino que se debe a la característica general de las palabras de valor: es axiológica, no ética, estética, etc. Las oraciones que atribuyen bondad a algo, si bien no son prescriptivas de la misma manera directa que las oraciones de deber ser, se aproximan a serlo, pues su propósito es siempre el de orientar elecciones, cuando menos indirectamente. Los juicios éticos acerca de nuestros propios actos futuros son, para Hare, decisiones; por tanto, difícilmente puede uno dar una explicación de ellos que admita la posibilidad de ir voluntariamente contra los propios juicios éticos de uno. Hay casos en que "bueno" puede usarse descriptivamente: cuando hemos decidido cuáles son las características por las que recomendamos cierta clase de cosa, podemos entonces usar "bueno" sólo para significar que el objeto a que se aplica tiene estas características fácticas, pero este uso es derivativo y secundario.

Hare arriba a su caracterización recomendatoria del valor del mismo modo que Edwards y otros a su caracterización emotiva: mediante la falta de determinación de la relación entre la propiedad de valor y las propiedades hacedoras de valor de una cosa buena ("good-making properties"). Al igual que Aristóteles y Edwards, Hare no puede encontrar el rasgo común de todas las cosas buenas en sus propiedades hacedoras de valor; y, por tanto, en lugar de definir lógicamente la bondad por medio de tales propiedades, debe pasar a un rasgo no-lógico -o según la escuela de Oxford, neo-lógico- poseído en común por todas las cosas buenas: su rasgo recomendatorio. Este rasgo, cree Hare, es constante en el significado de "bueno" para toda clase de objetos. Hare lo llama el significado valorativo de "bueno", en tanto que el significado descriptivo es el que comunican las propiedades hacedoras de lo bueno. Este último, según Hare, no constituye el significado de "bueno", sino meramente criterios de su aplicación. El significado de "bueno" es el valorativo, que expresa nuestra capacidad de elegir. Cuando llamamos bueno a un automóvil, o a un cronómetro o a una raqueta de tenis, los estamos recomendando a todos, queriendo decir que los elegiríamos para fines particulares. Pero, porque los recomendamos a todos por diferentes razones, el significado descriptivo de "bueno" es diferente en todos los casos. Es lo que Aristóteles llama homónimo y Edwards poliguo. Así como Aristóteles y Edwards eludieron esta diversidad del significado descriptivo, el primero mediante su definición de la virtud como una disposición a gobernar nuestras elecciones - como observa Hare en un lema- y el segundo considerando que el valor está envuelto en nuestra actitud, Hare lo elude haciendo de la elección el 'rasgo fundamental de valor.

Ningún axiólogo ha visto todavía lo que es fundamental en la ciencia: 
que lo que trasciende y explica todos los casos especificos no es otra clase de tales casos, sino únicamente la forma lógica. El sustituto de Hare para esta forma es especialmente interesante, puesto que él trata de darle al sustituto todas las propiedades lógicas de la cosa verdadera. Una vez que sabemos cómo elegir, cree Hare, sabemos cómo juzgar las propiedades hacedoras de bueno de las cosas, no importa cómo puedan cambiar en casos particulares. Tenemos conocimiento del significado valorativo de "bueno" desde nuestra edad más temprana; pero estamos aprendiendo constantemente a usarlo en nuevos significados descriptivos, a medida que las clases de objetos cuyas virtudes aprendemos a distinguir se hacen más numerosas. Debido a esta constancia del significado valorativo, en oposición a la inconstancia del significado descriptivo, Hare da primacía al primero. Podría objetarse, desde luego, que también el significado descriptivo seria constante con tal que la relación entre dicho significado descriptivo y el rasgo de valor estuviera lógicamente determinada. En este caso, desde luego, la razón de Hare para la primacía del significado valorativo $\mathrm{y}$, ciertamente, para este significado del todo, desaparecería. El significado descriptivo sería al mismo tiempo, aunque en otro aspecto, el significado valorativo. Hare se aproxima mucho a una tal determinación - tanto, por cierto, que Rice 28 tiene la impresión de que Hare puede quizá haber tropezado con una definición del valor cognoscitivo en el valor sin darse cuenta de ello. Hare encuentra que la relación entre una expresión de valor, tal como "un buen automóvil", y los criterios de su aplicación, es muy similar a la relación entre una expresión descriptiva - por ejemplo, "automóvil"- y. sus caracteristicas definitorias; en otras palabras, la primera relación - la de valorhecho- es muy similar a la relación entre definiendum y definiens. Esta analogía se encuentra, desde luego, en la base del axioma de la axiología formal: una cosa es buena si tiene sus propiedades definitorias. Hare se aproxima a este axioma tanto como puede hacerlo una explicación categorial más bien que axiomática. "Cuando yo recomiendo un automóvil, estoy orientando las elecciones de mi oyente no tan sólo en relación con ese automóvil particular, sino en relación con los automóviles en general. Lo que le he dicho le será de utilidad cada vez que tenga que escoger un automóvil en el futuro... Este proceso tiene, como hemos observado, ciertos rasgos en común con el proceso de definir (hacer conocido el significado - la aplicación de) una palabra descriptiva." 29 Una vez conocida la identidad axiológica de la valoración y la definición, el rasgo recomendatorio de Hare aparece como un velo tendido sobre el significado lógico de la valoración, velo cuya misma tenuidad lo hace tanto más frustratorio. Hare casi explica la naturaleza lógica del valor, y la razón de que no lo haga

28 On the Knowledge of Good and Evil, Nueva York, 1955, pág. 89.

20 Hare, op. cit., pág. 132. Cf. La estructura del valor, del autor, págs. 44 sig. 
plenamente -aun cuando usa libremente la palabra "lógica"- es que todavía está atrapado en el método categorial de la ética anticuada. Hare llega a reemplazar "virtudes" con el término descriptivo "características hacedoras de bueno", pero no llega a identificar estas últimas con el término lógico "características definitorias", o a identificar las primeras o las segundas con el significado de bueno. Por otra parte, ve claramente que este significado es un significado conceptual más bien que descriptivo; ${ }^{30}$ y al echar un velo sobre esta comprensión, envolviéndola en la membrana del "recomendar", su teoría del valor viene a ser como una crisálida que oculta la mariposa de la axiología formal.

Esto es igualmente claro en la segunda razón de Hare -la primera es la "constancia" del significado valorativo- para llamar al significado valorativo primario y al descriptivo secundario: que usamos la fuerza valorativa de la palabra a fin de cambiar el significado descriptivo de cualquier clase de objetos. Por ejemplo, un automóvil con las propiedades $a, b, c$ puede haber sido llamado bueno hace diez años, pero otro automóvil con las propiedades $e, f, g$ es llamado bueno hoy día. Aquí se usa el significado valorativo de la palabra a fin de trasladar el significado descriptivo. Estamos haciendo lo que se llamaría, si "bueno" fuera una palabra puramente descriptiva, redefinirlo. Pero no podemos llamarlo así, pues el significado valorativo permanece constante. Lo que hacemos es alterar la norma. Contra este argumento puede observarse que no hay ninguna razón por la que no debamos considerar la definición misma como una norma. "Bueno" sería entonces una palabra lógica, significando simplemente que una cosa satisface su definición. Este significado de "bueno" sería constante, no dependería de ninguna definición particular ni de ningún conjunto de propiedades, tales como las de los automóviles, sino que se referiría a cualquier definición y a cualquier totalidad de propiedades determinadas por ella. En este caso, la segunda razón para la preferencia por parte de Hare del significado valorativo en oposición al significado descriptivo de "bueno" desaparecería también.

La factibilidad de tal definición de "bueno" queda mostrada en la fuen. te misma donde Hare encuentra su lema para "bueno". El Diccionario de Inglés de Oxford, después de afirmar que "bueno" es "el adjetivo más general de recomendación", añade como significado de "bueno": "De las

30 Véase especialmente el Cap. 8, "Commending and Choosing", que ve las propiedades conceptuales de lo que es recomendado y elegido, pero no toma en serio esta perspicacia lógica. "Explica" una relación lógica por medio de una seudo-lógica, la de "recomendar", y no vice-versa; del mismo modo que Aristóteles explicó la lógica por medio de la telcología, y no vice-versa (véase pág. 97 de La estructura del valor). Tenemos aquí una definición de notum per ignotum, que se encuentra un peldaño más abajo en la rareza lógica - para usar un término de la "lógica" contextual - que la explicación de ignotum per ignotius. 
cosas: Ser lo que se les llama a éstas." Ésta es precisamente la definición de lo bueno extrínseco en la axiología formal. Es una fórmula, constante para todas las cosas tales como cronómetros, raquetas de tenis, etc.; además, puede ser desarrollada sistemáticamente y extendida al valor intrinseco y a otras formas de valores, como no puede hacerse con un concepto analítico. La fórmula toma la definición misma como norma. El prejuicio de Hare contra el uso de la lógica "anticuada" en el análisis del valor se debe a la infección wittgensteiniana de su escuela, que le impide ver lo simple en lo complejo - a saber, lo puramente lógico y conceptual- y lo lleva, en oposición a la navaja de Ockham, a multiplicar entidades más allá de la necesidad: "Un lógico no puede hacer justicia a las infinitas sutilezas del lenguaje... Una comprensión plena de la lógica de los términos de valor sólo puede alcanzarse prestando atención constante y sensitiva a la manera en que los usamos". 31 La axiología formal demuestra que la lógica del valor es como cualquier clase de lógica y la definición del valor como cualquier definición, a saber, una fórmula que abarca y explica los usos de los términos, del mismo modo que lo hace una fórmula en la ciencia.

Nowell-Smith ${ }^{32}$ adopta un punto de vista bastante similar al de Hare. El también argumenta que no podríamos deducir que debemos hacer algo a partir de características no-naturales objetivas más que de caracteristicas naturales. Lo que el intuicionista hace realmente es invitarnos a considerar que la experiencia moral (o valorativa) es análoga a ver; pero la analogía no será sostenible, pues la terminología objetivista implica que hay pruebas (tests) aceptadas por todos, y tales pruebas faltan en la ética, de modo que los términos "correcto" y "erróneo", "verdadero" y "falso" no pueden ser aplicados significativamente. Esta objeción, similar a la objeción kantiana contra la metafísica tradicional, es válida sólo si la analogía es concebida empíricamente de manera ingenua. Si "ver" en la filosofía de Moore se concibe fenomenológicamente, y si "simplicidad" de bondad significa simplicidad axiomática, entonces la "prueba" será la coherencia y aplicabilidad del resultante sistema ético sintético. $\mathrm{Ni}$ Moore ni ningún otro axiólogo ha considerado hasta ahora esta posibilidad, que es realmente la única que da sentido a la filosofía del valor de Moore en todos sus aspectos. NowellSmith no encontró la clave de una ética científica en el propio Moore porque no pudo imaginar una propiedad que no fuera empirica y sin embargo fuera lógica, en el sentido usual de esta palabra. El concuerda, con reservas, con Moore en que el discurso moral es diferente del discurso naturalista y los predicados morales son diferentes de los predicados descriptivos. Pero cree que sólo los últimos se refieren a propiedades y los primeros no, considerando como propiedades "los ejemplos típicos del lógico, como 'azul',

31 Hare, op. cit., pág. 126.

32 Ethics, Londres, 1954. 
'ruidoso' y 'redondo'".33 'Partiendo de este supuesto erróneo, reprocha a Moore el llamar "buena" una propiedad, pues esto significaría que su lógica sería la misma que la de los adjetivos mencionados, cuando la idea de Moore era que la lógica de "bueno" era diferente de la de estos adjetivos. "Moore se propuso señalar una diferencia importante en status y comportamiento lógicos entre 'bueno' y 'amarillo'. Sin embargo, éste es precisamente el tipo de diferencia que se niega al decir que la bondad es una propiedad. Pues, ¿qué es decir que la bondad es una propiedad, sino decir que la lógica de 'bueno' es como la de otras palabras-propiedad? La terminología que Moore usó para señalar una diferencia importante que él observó entre 'bueno' y otros adjetivos era singularmente inadecuada para poner de manifiesto precisamente esta diferencia." 34

Desde luego, Moore nunca dijo “que la lógica de 'bueno' es como la de otras palabras-propiedad". Esto lo dice Nowell-Smith sobre la base de su propio supuesto erróneo. Él no ve que hay otros ejemplos para propiedades en el repertorio del lógico típico, diferentes de los ejemplos simples que él menciona - por ejemplo, propiedades de segundo orden, tales como "típico"-, 35 y que tales propiedades tienen una lógica diferente de la de las propiedades de primer orden. De tal suerte, "bueno" bien puede ser una propiedad y sin embargo tener una lógica diferente de la de las propiedades descriptivas. Más aún, esta lógica es parte de la lógica usual en el sentido técnico; y ella no sólo muestra una conexión lógica entre la propiedad "bueno" y las propiedades hacedoras de bueno de una cosa, sino que también concuerda con el propio enfoque de Moore al problema de la bondad.

Nowell-Smith, no viendo estas conexiones, $y$, sin embargo, consciente hasta cierto punto de lo correcto de la falacia naturalista, debe apoyarse en el recurso de una lógica especial, inventada ad hoc y que no sólo contradice su reconocimiento de la falacia naturalista, sino que lo conduce a incurrir en ella. Nowell-Smith identifica las propiedades descriptivas de Moore con propiedades sensoriales empíricas, $y$, por lo tanto, las propiedades no-naturales y no-descriptivas de Moore con propiedades no-empíricas, no-sensoriales, probadas por algo diferente de la percepción sensorial y que ponen en juego "un acto especial de conciencia" ("a special act of awareness"), 36 un acto de emoción. Y, puesto que Nowell-Smith sostiene que los diferentes tipos de conciencia (awareness) pertenecen a la lógica de los respectivos tipos de palabras, la diferencia implica que no puede haber conexión lógica entre la bondad y las propiedades hacedoras de bueno, pues

33 Op. cit., pág. 64.

34 Op. cit., pág. 65.

35 Bertrand Russell, Introduction to Mathematical Philosophy, Londres, 193 ${ }^{R}$, pág. 189; An Inquiry into Meaning and Truth, Nueva York, 194o, págs. 252 sig. Véase La estructura del valor, págs. 231 sigs.

36 Nowell-Smith, op. cit., pág. 71 . 
cada una tiene su propia lógica distinta. ${ }^{37}$ AI sostener así que la naturaleza sensorial de los "ejemplos del lógico típico" de propiedades es parte de la naturaleza lógica de los predicados correspondientes, y que la naturaleza emocional de los ejemplos de propiedades de valor del lógico ético, tales como "sublime" o "bueno", es parte de la naturaleza lógica de los predicados de valor correspondientes, Nowell-Smith confunde la lógica con la psicología e incurre en la falacia del método: confunde la estructura del lenguaje con la conformación psicológica de la persona que usa el lenguaje. Esto, consecuentemente, lo conduce a la falacia naturalista: el contexto psicológico de las palabras de valor se confunde con su contexto ético. La lógica de las "palabras-propiedad" se confunde con el contexto del discurso empírico, y la lógica de las palabras de valor con el contexto del discurso emotivo. Lo primero es la falacia del método, lo segundo es la falacia naturalista.

Moore distingue claramente estos niveles diferentes y los expresa a su propia manera, que es paradójica. Nowell-Smith, cuyo temperamento es contrario a las distinciones claras, sólo ve la paradoja; y en lugar de encontrar en la filosofía de Moore la clave para una ética científica sobre la base de la lógica técnica rigurosa, inventa su propia lógica, "recurrien. do lo menos posible a los términos técnicos de la lógica tradicional", 38 y al hacer tal cosa abraza el método wittgensteiniano. El resultado es una lógica que carece de las distinciones fundamentales de la verdadera lógica, una lógica sin rigor, cuya "deliberada vaguedad" ${ }^{39}$ está perfectamente adaptada a "las perezosas consecuencias" que Russell vio en la doctrina wittgensteiniana. Las palabras son sacadas de la esfera del pensamiento y colocadas en la esfera de la acción: se convierten en actores en el discurso más bien que en elementos de la discursividad. La lógica viene a ser la coreografía de los movimientos, la descripción pragmática del comportamiento de las palabras. "En lugar de la pregunta '¿Qué significa la palabra...?', sustituiré por lo tanto las dos preguntas ‘Para qué tarea se usa la palabra...?’ y ‘¿Bajo qué condiciones es apropiado usar esta palabra para esa tarea?’... Simplemente abandonaré el modelo familiar de palabras como etiquetas pegadas a las cosas y las trataré como herramientas con las cuales hacer cosas. Hablar no es siempre nombrar o informar; algunas veces es hacer". ${ }^{40}$ De tal suerte, Nowell-Smith afirma con claridad que basa su programa en lo que nosotros llamamos la falacia del método.41

37 Op. cit., págs. $58,71$.

38 Op. cit., pág. 6g.

39 Op. cit., pág. $7^{2}$.

40 Ibid.

$41 \mathrm{La}$ estructura del valor, Introducción y passim. Es posible que todas las palabras que son acciones tengan un matiz ético, e. g. "†Fuegol" o "Te amo", pero no es la ver- 
Su lógica, entonces, viene a ser la coreografía del comportamiento de las palabras. Las palabras exhiben el "comportamiento lógico": "Si examinamos los adjetivos utilizados en el discurso ordinario, encontramos que ellos exhiben una gran variedad de comportamiento lógico. La forma gramática de un adjetivo nos da algunas. veces un indicio de su comportamiento lógico; por ejemplo, los adjetivos terminados en -ente, -ible, -oso e -ico se agrupan en familias que difieren lógicamente entre sí, y frecuentemente podemos decir algo sobre el significado de un nuevo adjetivo según cuál sea su terminación, del mismo modo que un químico podría deducir algo acerca de un compuesto desconocido para el partiendo del hecho de que su nombre termina en -ito, -uro o -ato. Pero la terminación no es una guía del todo confiable para el comportamiento lógico..." 42 La comparación con la química pone de manifiesto la confusión del procedimiento de NowellSmith. El químico puede deducir algo sobre un compuesto desconocido para él partiendo del nombre del compuesto porque el nombre es parte de un sistema y fue inventado para encajar en él; y el nombre del uso común del compuesto fue abolido expresamente. ${ }^{43}$ Por tanto, o bien la comparación de Nowell-Smith presupone un Lavoisier del lenguaje moral, o bien su ejemplo debe de referirse a la alquimia y no a la química. Puesto que él aborrece la disciplina creadora de sistema de un Lavoisier, su ejemplo debe de referirse a la alquimia. Esto, a su vez, muestra la naturaleza alquímica de su uso del lenguaje.

Como un buen alquimista, Nowell-Smith utiliza una herramienta para proporcionar una apariencia de orden en el caos del comportamiento de las palabras que tiene todas las características de una varita mágica. Su nombre es "rareza lógica" (logical oddness). Una pregunta es considerada " 'lógicamente rara' ('logically odd') si parece no haber más espacio para ella en su contexto lógico porque ya ha sido contestada". ${ }^{44}$ Sería lógicamente raro preguntarle a un hombre que está saboreando un puro si lo está disfrutando. Es lógicamente raro preguntar a una persona que está dando razones para elegir una manera de obrar por qué esas razones le condujeron a elegir dicha manera de obrar. La "rareza lógica" es, pues, un artificio que elimina todas las preguntas tocantes a la justificación no-contextual. Es una varita mágica que hace desaparecer por un escotillón las preguntas incómodas; una herramienta "lógica" que detiene la curiosidad axiológica. "¿Por qué es la existencia de una deuda una razón para pagarla?" Esta pregunta es lógicamente rara una vez que yo haya dicho que

dad que todas las palabras éticas tengan un matiz de acción, e. g. "El valor supremo es la contemplación".

42 Op. cit., pág. 7o.

43 Véase La estructura del valor, págs. $64,198$.

44 Op. cit., págs. 83 sig. 
pago porque debo. Serfa lógicamente raro entrar en una discusión acerca de la naturaleza de la obligación legal, su relación con la obligación moral, etcétera; y lo que es tan particularmente raro en esta teoría es que la rareza lógica es aplicable tanto al agente en la situación como al filósofo ético que se ocupa de ella. El filósofo wittgensteiniano no debe superar el caos de los contextos sino hacerse parte de él. Todo lo que puede hacer es inspecciones, y así todo lo que Nowell-Smith propone hacer en su Ética es "discutir las maneras en que las diferentes palabras de razones [contextuales] encajan las unas en las otras": "55 una especie de juego de rompecabezas en que se hacen encajar piezas verbales, pero no en un todo. La regla de la "rareza lógica" es el artificio para asegurarse de que nadie hará trampa en el juego y mirará el cuadro total del rompecabezas.

Para Nowell-Smith, los juicios de deber ser (ought-judgments) sobre nuestras propias acciones son decisiones o elecciones. De esto extrae la conclusión de que hay algo "lógicamente raro" en no hacer lo que pienso que debo hacer, y similarmente en no elegir lo que pienso que es mejor.46 Empero, rechaza como una simplificación excesiva la concepción de que las oraciones de deber ser son órdenes disfrazadas. ${ }^{47}$ "Usamos las oraciones de 'usted debe' precisamente cuando no estamos en posición de dar órdenes; y este hecho y el hecho de que estas oraciones deben estar respaldadas por razones, constituyen una clave importante de su lógica." 48 Nowell-Smith sugiere, en buen estilo wittgensteiniano, que la significación de "deber ser" varía ampliamente según el contexto y no puede reducirse a ninguna sola función, aun si nos limitamos al "deber ser" distintivamente moral.49 Nowell-Smith considera un "desastre" y una causa principal del error del objetivismo el que "deber ser" haya sido separado de su pronombre-sujeto, siendo así que la palabra tiene una función muy diferente en "yo debo" y "usted debe".50 En relación con otras personas, es mejor pensar en las oraciones de deber ser en el sentido de dar consejo que de dar órdenes, aunque "consejo" es con frecuencia una palabra demasiado débil; 51 en relación con uno mismo, tales oraciones expresan elecciones más bien que órdenes.

45 Op. cit., pág. 84 .

46 Op. cit., págs. 102 sigs., 160.

47 Op. cit., págs. 191-193.

48 Op. cit., pág. 192.

49 No se investiga por qué el "debe moral" debe variar menos ampliamente que el "debe". Tenemos aquí la ingenua confianza en la sabiduría del lenguaje ordinario que ios filósofos del valor categoriales tienen en común con los filósofos naturales precientíficos. Puesto que "debe" parece ser un género y "debe moral" una especie, parece obvio que, si ambos "varían ampliamente", el primero debe variar más ampliamente que el segundo. Pero, axomáticamente, esto es un desatino. Si el "debe moral" es una aplicación del "debe", el primero varía más ampliamente que el segundo, del mismo. modo que hay más variación real en los círculos reales que en el círculo geométrico.

60 Op. cit., págs. 193-197.

51 op. cit., pág. 192 . 
Tenemos aquí una vez más el análisis de muestreo o "espécimen" de los términos éticos. El uso "cognoscitivo" de estos términos está "tan íntimamente ligado con el contexto en que ocurren los términos, que resulta seriamente engañoso hacerlos explícitos mediante el proceso ordinario de definición. Más bien debemos examinar los términos cuando,éstos están en acción, ejemplo por ejemplo, señalando en cada caso qué tipo de información tienen que comunicar". La finalidad del libro no es, pues, contestar a las preguntas de la ética: ¿Qué debo hacer aquí y ahora?, ¿Qué debo hacer en general?, ¿Por qué debo atenerme en todo caso a un código moral?, sino más bien "hacer clara la complicada conexión entre palabras tales como 'bueno', 'correcto', 'debe', 'elegir', 'deber', 'deseo', 'placer', etc.", todas ellas como piezas del rompecabezas, mediante el muestreo fragmentario $o$, a lo sumo, mediante la clasificación primitiva de acuerdo con el "comportamiento" contextual de las palabras, más bien que como ejemplos de un orden sistemático.

Siguiendo este programa wittgensteiniano -que, en la filosofía natural, correspondería a un programa con reglas estrictas contra todo tipo de pensamiento que no sea el más ordinario, un programa militantemente alquimista-, Nowell-Smith forma tres grandes familias de uso de palabras: usos-A (palabras-A), usos-D (palabras-D) y usos-G (palabras-G). Las primeras son palabras de aptitud, indicativas de que un objeto tiene ciertas propiedades que son ap̣tas para suscitar cierta emoción o gama de emociones en nosotros, tales como "sublime" o "cómodo"; las segundas son palabras descriptivas, como "rojo" o "amarillo"; y las terceras son palabras gerundiales, que nos instan a hacer algo, tales como "encomiable", "lamentable", "condenable", etcétera. "Un vestido puede ser rojo, cómodo e indecente... Un hombre puede ser rubio, divertido y admirable." 52 Las tres clases de palabras están sujetas a tres clases de "lógica". Para entender la lógica de las oraciones-A, debemos preguntar, no qué significa (siempre) la oración, sino qué implica contextualmente su uso en este caso.53 Los elementos "implicados contextualmente" en usos típicos son el elemento subjetivo, el predictivo, el generalizador y el causal. El elemento subjetivo quiere decir que, en ausencia de otra evidencia, el uso de una oración-A implica usualmente que el que habla tiene la reacción apropiada; el predictivo quiere decir que cualquier persona tendría la reacción apropiada si surgieran circunstancias adecuadas; el generalizador quiere decir que un hombre que usa una afirmación en oración-A, tal como una predicción, implica contextualmente que tiene lo que considera ser una buena razón para hacer la-predicción; y el elemento causal se refiere a las propiedades contextualmente implicadas por la palabra que dan la ca-

52 Op. cit., pág. 73 .

53 "Implicación contextual" significa a) ninguna implicación lógica, b) conexiones de sentido común entre un hablante y su situación (op. cit., págs. 81 sig.). 
racterística de valor que ésta tiene; por ejemplo, buenos muelles, un calentador y mucha amplitud son los elementos causales que hacen que un automóvil sea cómodo. Son lo que otros autores llaman propiedades hacedoras de bueno. Por falta de toda relación estrictamente lógica -en el sentido tradicional de la palabra - ellas están, para Nowell-Smith, como para muchos otros autores, relacionadas causalmente con la propiedad de valor; y esta relación causal se convierte en un elemento de la neo-lógica contextual.

Esta lógica, aplicada a la palabra "bueno", examina el uso de "bueno" en diversos contextos, ${ }^{54}$ aplicándose a estos contextos la lógica de las tres fa. milias de palabras. "Bueno" se usa en el contexto de elección, de consejo, de elogiar y aplaudir, de veredictos y apreciaciones, de eficiencia y habilidad, y también descriptivamente. En el contexto de elección presupone una propiedad-A y alguna propiedad empírica ordinaria de la cual depende la propiedad-A. Mientras que la respuesta fáctica a la pregunta: "¿Por qué eligió usted este automóvil?" dice cuáles son las propiedades empíricas ("porque tiene mucha amplitud") e implica contextualmente una propiedad-A ("cómodo") sin especificar cuál es, la respuesta-A ("porque es cómodo") hace lo inverso, especifica la propiedad-A ("cómodo") e implica contextualmente la propiedad empírica ("amplitud", etc.). La bondad de algo no es una de las propiedades por las que yo elijo. Decir que lo es sería "como decir que me asusté porque fue una experiencia aterradora", o como la explicación alquímica del sueño como la cualidad dormitiva. Más bien, "bueno" señala propiedades "hacedoras de bueno", y éstas son las razones por las que yo elijo. Decir que elijo una cosa "porque es buena" muestra que estoy eligiendo, pero no por qué lo hago.

Vemos aquí la naturaleza lógica de "bueno" - la cosa es elegida como buena porque satisface sus propiedades intensionales - velada en un contexto seudo-lógico, el de la causalidad de la "elección". Hay, dice Nowell-Smith, "ataduras lógicas que ligan la bondad... íntimamente con la elección"; pero su naturaleza lógica es material, "contextual", y no formal; y, por tanto, seudo-lógica más bien que lógica. La atadura no es lo bastante estrecha; y en modo alguno es desusado, no digamos raro, no digamos "lógicamente" raro, llamar a algo "bueno", "mejor" y aun "lo mejor" y sin embargo no elegirlo. "Ella es la mejor prostituta de la ciudad" no significa que yo tengo una actitud-pro hacia ella; y "Ella es una muchacha realmente buena" puede usarse en realidad para justificar una actitud-anti, pues a mi me gustan las "muchachas malas". Tales "excepciones" son el signo típico de las conjeturas analíticas más bien que de la penetración sintética; y ellas son el orgullo de la lógica "práctica". Los sustitutos contextuales de la penetración axiológica no explican la realidad del valor, ni siquiera el lenguaje del valor ordinario. Más bien ponen de manifiesto la naturaleza inútil de la "implicación contex-

64 Op. cit., Cap. 12. Las citas siguientes son de la pág. 161. 
tual", un cógelotodo que realmente no coge nada, y la naturaleza tramposa de la "rareza lógica", un escotillón que se abre tan pronto como se acerca una mente con una curiosidad axiológica que sobrepase aunque sea ligeramente la del hombre corriente. Toda interrogación axiológica algo más profunda, por no decir la verdadera problemática axiológica, viene a ser "lógicamente rara". El filósofo viene a ser una especie de excéntrico. Y el sostener que la verdadera explicación axiológica sólo debe ser posible en un nivel de lenguaje superior al ordinario, se juzga "positiva y enfáticamente" como "desastroso".

Los "contextos" de Nowell-Smith - "elección", "eficiencia", etc.- son conceptos analíticos o categorías que desfilan bajo el disfraz de una "lógica práctica" que oculta su naturaleza teóricamente lógica. Su implicatividad categorial se convierte así en una implicatividad "contextual"; y si la primera es vaga, la segunda casi carece de significado: "a diferencia de las reglas de la implicación lógica, las reglas de la implicación contextual pueden ser violadas todas ellas sin que el que habla se vea envuelto en la contradicción o el absurdo".55 De tal suerte, ignotum es "explicado" por ignotius. Y todos estos "contextos" son únicamente maneras diferentes de velar la naturaleza verdaderamente lógica de la bondad.

Esto es especialmente notable en el caso de los contextos de eficiencia y habilidad. En el contexto de eficiencia, "bueno" es predicado acerca de cualquier objeto usado con un propósito: "bueno" implica la presencia, en un grado relativamente alto, de estas propiedades que el objeto debe tener para cumplir su función. Pero también sería un error, según Nowell-Smith, decir que "buen cuchillo" sólo significa "cuchillo que es afilado, fácilmente manejable, durable, etc." La conexión entre las propiedades que un cuchillo debe tener para ser eficiente y su eficiencia es una conexión empírica. Sabemos por experiencia que un cuchillo que carezca absolutamente de estas propiedades sencillamente no cortará, y que su eficiencia relativa para cortar depende del grado en que tenga estas propiedades. Tampoco podemos decir nunca que "buen cuchillo" significa "cuchillo que corta eficientemente", porque podríamos saber lo que significa "bueno" en la expresión "buen cuchillo" sin saber para qué sirven los cuchillos. Más biẹn, "buen cuchillo" (en este sentido de "bueno") significa "cuchillo que tiene aquellas propiedades (sean lo que fueren) que un cuchillo debe tener para cumplir eficientemente su función (sea la que fuere)". ${ }^{56}$ Aquí la naturaleza conceptual, y por lo tanto formalmente lógica, de "bueno" casi salta a los ojos del lector, pero sin ser reconocida por el autor. En el contexto de habilidad - cuando llamamos a un hombre un buen abogado, erudito, futbolista o embustero- el uso es similar al uso de "eficiencia", excepto por el hecho de que, puesto que éstos

55 Op. cit., pág. 81.

56 Op. cit., págs. 165 sig. 
son hombres, el propósito en cuestión es su propósito, no el propósito para el cual ellos son usados. ${ }^{57}$

Así pues, "bueno", dice Nowell-Smith, "es la palabra-Jano por excelencia; es usada frecuentemente para cumplir más de una función en una ocasión; y las conexiones lógicas entre las diversas funciones son las que son porque los hechos son los que son. Es también, de la manera más enfática, una palabra ordinaria, no-técnica, y es consecuencia de esto el que la lógica de su uso refleje verdades empíricas que rigen sólo para la mayor parte $y$ admiten excepciones; pues el lenguaje ordinario, a diferencia de las matemáticas, no es deliberadamente construido por hombres dotados de un buen sentido de la consistencia y del rigor; no es construido deliberadamente en modo alguno, sino que crece y cambia" 58 en su medio ambiente.

Aquí vemos claramente la confusión wittgensteiniana entre la filosofía y su asunto. El lenguaje ordinario incluye palabras numéricas del mismo modo que incluye palabras morales. $\mathrm{Y}$ cuando un chofer de camión le dice a otro: "Te estás buscando una o dos trompadas", está usando "una" y "dos", de la manera más enfática, como palabras ordinarias no-técnicas. Tal uso nunca les ha impedido a Jos matemáticos construir los mismos términos, "uno", "dos", técnica y lógicamente en un sentido formal, creando así un nivel superior de lenguaje numérico llamado matemáticas. Del mismo modo, aunque hay un uso contextual ordinario de palabras de valor tales como "bueno", "malo", etc., ello no tiene que impedirles a los axiólogos construir los mismos términos técnica y lógicamente en un sentido formal, creando así un nivel superior de lenguaje moral llamado axiología formal. Oponer el lenguaje moral ordinario al lenguaje numérico formal, como hace Nowell-Smith en el pasaje citado, es metodológicamente ilícito. Lo que puede oponerse de manera metodológicamente correcta es el lenguaje ordinario y el lenguaje formal; y el lenguaje moral y el lenguaje numérico. Las correspondencias respectivas son, entonces, el lenguaje moral ordinario y el lenguaje numérico ordinario, y el lenguaje moral formal y el lenguaje numérico formal; y las oposiciones respectivas son el lenguaje moral ordinario y el lenguaje moral formal, y el lenguaje numérico ordinario y el lenguaje numérico formal. Pasar por alto el lenguaje moral formal y el lenguaje numérico ordinario es arbitrario; es lógica y metodológicamente no sólo raro, sino falaz. Y el énfasis no es un correctivo para la falacia lógica.

Aunque, según Nowell-Smith, las implicaciones contextuales de los usos de "bueno" son demasiadas y demasiado variadas para ser explicables en términos conceptuales, él no puede abstenerse de incurrir en la generalización absoluta. "Hay un elemento que parece ser común a todos los casos. Aunque un hombre no tiene que hacer necesariamente una comparación cuando

57 Op. cit., pág. 166.

58 Op. cit., pág. 167 . Cf. pág. $97 n$. 
llama a algo bueno, tales comparaciones están siempre implicadas." 50 Éstas son comparaciones en grados de sentimiento. "Siempre elogiamos con cierto grado de entusiasmo lo que se encuentra en algún punto de una escala entre la recomendación moderada y la adulación histérica. La palabra 'bueno' puede usarse para expresar casi cualquier grado de entusiasmo, pero éste debe ser menor que el que se expresa en el mismo contexto por medio de 'excelente' o 'super', y mayor que el que se expresa por medio de 'regular' o 'tolerable" ".60 Nowell-Smith piensa que no es difícil entender las conexiones entre los diversos contextos de "bueno", "los usos más obviamente ejecutorios, elogiar, aplaudir y recomendar; ni tampoco apreciar su conexión íntima con la preferencia y la elección. Elogiar no es elegir, pero está conectado con la elección en cuanto que sería raro que un hombre eligiera la cosa que está preparado para elogiar en el menor grado o para no elogiarla en absoluto... Elogiar está lógicamente ligado con la aprobación, pues si oyéramos a un hombre elogiar algo, no dudaríamos de que lo aprueba a menos que sospechásemos doblez o ironía en él; y está lógicamente ligado de la misma manera con el estímulo... Las mismas ataduras lógicas ligan el elogio con el consejo; scría lógicamente raro elogiar más a un candidato que a otro y decir a continuación que estamos en contra de que se le dé el puesto o el premio". ${ }^{11}$ Todos estos usos, pues, están "conectados" por la rareza lógica, un vínculo muy débil aun cuando fuera verdadero, que no lo es. Puedo decir que Jruschov es mucho mejor que Stalin, sin aprobar por ello que sea el gobernante de Rusia. La lógica conceptual quiebra tan pronto se cuestionan los contextos. Puedo elogiar dentro de un contexto y condenar el contexto. En realidad, los problemas moralmente profundos son de este tipo; de ahí la superficialidad de esta ética tan artificiosa, su combinación de la trivialidad práctica con la complicación teórica.

Nowell-Smith cree que esta lógica contextual es la que nos dará una comprensión de la naturaleza del lenguaje del valor y que no hay confusión más importante y difundida que la de transferir al análisis del cliscurso moral los conceptos lógicos que se utilizan con buen éxito para elucidar el discurso de las matemáticas o la ciencia. "Esto ha llevado a los filósofos a representar falsamente el saber cómo conducir nuestra vida como el conocimiento de verdades teóricas, ya sea acerca de la naturaleza humana o acerca de una esfera real de 'valores'. Este error, combinado con la comprensión de que las verdades de hecho no entrañan imperativos y de que ni las verdades de hecho ni los imperativos entrañan decisiones, ha conducido a la doctrina de que las palabras morales deben representar ciertas entidades y a la postulación de una facultad especial que explique nuestro conocimiento de las ver-

59 Ibid.

co Op. cit., págs. 167 sig.

61 Op. cit., págs. 168 sig. 
dades morales. La diferencia crucial entre el discurso práctico y el teórico ha sido representada falsamente como una diferencia entre conjuntos de objetos descritos, en lugar de haber sido representada como una diferencia en el papel desempeñado por diferentes tipos de expresión." 62

Aunque las palabras de valor son sui generis y no pueden ser definidas, como correctamente sostuvo Moore, en términos de placer, de deseo y ni siquiera de propósito, Nowell-Smith cree que "la psicología no es tan impertinente a la ética como afirman algunos filósofos modernos; pues, aunque los juicios morales no se desprenden de afirmaciones psicológicas, no podemos entender lo que significan los términos usados en los juicios morales a menos que los examinemos en el contexto de su uso; y ellos son usados ya sea directamente para expresar una actitud en pro o en contra, ya sea para ejecutar alguna otra tarea que no podrían ejecutar ni entender siquiera seres que no tuvieran una actitud en pro o en contra". ${ }^{63}$ El lenguaje de valor es inteligible sólo en conexión con el lenguaje de propósito y elección: los hombres eligen hacer lo que hacen porque son lo que son; "y las teorías morales que tratan de excluir toda consideración de la naturaleza humana tal como ésta es, no comienzan siquiera a ser teorías morales".04 Aqui tenemos el naturalismo que hemos mencionado anteriormente y que, lingüísticamente disfrazado, autores como Stroll ca han encontrado en la escuela emotivista y autores como Hall ${ }^{66}$ en la Escuela de Oxford. Con todo, este naturalismo está mitigado por una vaga comprensión de la unicidad del hombre, utilizado no como un desafío para investigar esta unicidad, sino como una excusa para prescindir del pensamiento conceptual. "Las decisiones y los imperativos no se desprenden lógicamente de descripciones psicológicas o biológicas; pero el tipo de vida que será en realidad satisfactorio para un hombre dependerá del tipo de hombre que éste sea. La generalización es posible sólo en la medida en que los hombres son psicológica y biológicamente similares. Hay algunos tipos de vida que ningún hombre - podemos decirlo de plano- considerará satisfactorios; pero el consejo práctico no es necesario cuando es obvio. En casos que son difíciles de decidir, es vano, presuntuoso y peligroso tratar de resolver estas cuestiones sin un conocimiento tanto de la psicología como del caso individual... Las preguntas ¿Qué haré? y ¿Qué principios morales debo adoptar? debe contestarlas cada hombre por sí mismo; esto, cuando menos, es parte de la connotación de la palabra "moral'." 67

62 Op. cit., págs. 317 sig.

63 Op. cit., pág. 182. Este pasaje muestra el naturalismo de la definición de bueno, supuestamente no-naturalista, de A. C. Ewing. Véase XIII Congreso Internacional de Filolosofia, Symposium sobre Valor en genere y valores especificos. México, 1963, págs. 67 sigs. 64 Ibid.

65 The Emotive Theory of Ethics, Berkeley, 1954.

66 "Practical Reason (s) and the Deadlock in Ethics", Mind, 64, págs. 319-332 (1955). 67 Op. cit., págs. 319 sig. 
Pero qué parte es y qué significa precisamente es la pregunta a la que ninguna lógica contextual puede responder.

La posición semi-cognoscitivista de la Escuela de Oxford ha sido objeto de una crítica severa y en algunos casos definitiva. Tal posición, sostienen los críticos, es éticamente inarticulada y lógicamente inexacta. Sus juegos de palabras son prácticamente impertinentes y su detención de la indagación en el nivel descriptivo es lógicamente ilegítima. Langmead Casserley ${ }^{68}$ coincide con la Escuela de Oxford en su prejuicio contra la definición, pero por la razón contraria: en cuanto que la definición es demasiado estrecha. El ve la solución en la ampliación de la definición para abarcar la totalidad de la realidad del valor -como era el caso en el pensamiento medieval y clásico- más bien que en un retroceso a los significados de los contextos triviales. Lo que falta en la teoría ética es la aplicación pertinente a la realidad moral, y la razón de ello es que la ética está basada ya en una axiología demasiado estrecha. La mayoría de los sistemas modernos de teoría ética son lo que Casserley llama sistemas de "una sola clave", en los que alguna concepción soberana - tal como el placer, la utilidad, el llamado sentido moral, la elección o la eficiencia biológica - es utilizada para interpretar toda la gama de la experiencia moral. Una drástica simplificación excesiva de este tipo no sólo representa un alejamiento de la comprehensividad y el realismo de la teoría ética medieval, sino que también es inferior en todos estos respectos al mejor pensamiento clásico. La ética en el sentido tradicional se ha convertido en la víctima de las concepciones relativistas fragmentarias. "E1 verdadero prejuicio de la actitud contemporánea ante la ética se expresa en el relativismo social empírico, en el relativismo a priori- de los positivistas lógicos, y en lo que podría llamarse el relativismo metafísico realista de los existencialistas. Desde cualquiera de estos tres diversos puntos de vista, la teoría ética en el sentido convencional aparece como un sinsentido insustancial." 69

Lamentablemente, Casserley no alcanza a coronar su análisis correcto con la solución correcta. No percibe la naturaleza formal del problema: que la fragmentación de las doctrinas éticas no puede ser superada por otra doctrina semejante, sino únicamente por un nivel superior de lenguaje ético. Él ataca el problema materialmente más bien que formalmente; y esto es tanto más lamentable cuanto que de esta manera naufraga en el mismo escollo en que se ha encallado buena parte de la ética tradicional: la dificultad lógica de dar cuenta de la persona humana individual. Únicamente un lenguaje ético de nivel superior, una axiologia formal, puede resolver este problema.

La solución de Casserley es la metafísica religiosa, cuya grandeza y per-

68 Morals and Man in the Social Sciences, Londres, 1951.

60 Casserlcy, op. cit., pág. 77 . 
tinencia, dice él, ha demostrado la Edad Media. El hecho fundamental de la ética es el valor del hombre, y este valor no puede darse en el pensamiento secular sino únicamente en el religioso. El pensamiento religioso más estrecho resulta inevitablemente más amplio que el pensamiento secular más amplio. El pensamiento secular simplifica excesivamente el problema del hombre y falsea el carácter existencial de la existencia humana. El hombre no es una abstracción, sino que es toda la profundidad y anchura, toda la longitud y altura de la experiencia humana en y a través de una sola personalidad. El hombre no es un ser sociológico, sino un ser existencial y metafísico. Su valor es la unicidad. La exposición de Langmead Casserley culmina en una repetición de la distinción entre Naturwissenschaften y Geisteswissenschaften y demandando un análisis de las relaciones entre la ciencia y la generalización científica, por una parte, y la historia y la vida personal, por la otra. La unicidad del hombre puede ser estudiada científicamente, pero el autor no es consciente del alcance metodológico de su solución: el requisito de una comprensión sintética, formal, de la unicidad, que la naturaleza analítica material de las disciplinas a las que él confía la solución -historia, metafísica, teología - no satisfacen. Por tanto, la "grandeza y pertinencia" de la metafísica medieval para la valoración del hombre es meramente abstracta; no impidió las atrocidades que fueron la diversión normal del hombre medieval y no menos de aquellos cuya profesión era el estudio de la metafísica religiosa y la teología. ${ }^{70}$

Esta combinación de crítica frecuentemente aguda con carencia de soluciones positivas la encontramos en todas las críticas de la ética contemporánea, pues estas críticas son ellas mismas ética contemporánea, y analíticas más bien que sintéticas. Mientras que Casserley trata de superar el relativismo semi-cognoscitivista por medio de una especie de objetivismo metafísico, otros autores favorecen el objetivismo moral, epistemológico y diversas clases de objetivismo lógico.

70 Véanse páǵs. 106 sigs. de La estructura ảel valor. La concepción idealista de Casserley y otros respectos de la Edad Media - "el periodo medieval fue ciertamente una época grande y sabia en el desarrollo de nuestra cultura" (op. cit., pág. 85) - se debe a que los escritos medievales han sido tomados al pie de la letra y no han sido comprendidos axio-metodologicamente, como desarrollos meramente analíticos del pensamiento implicativo, cuya pertinencia a la vida de la persona individual era irracional. Estos escritos endurecieron tanto como suavizaron la vida medieval; y su pertinencia para el lector medieval fueron más a menudo las torturas del infierno que las delicias del cielo. Estos escritos son agradables de leer en el siglo $\mathrm{xx}$ precisamente debido a su impertinencia; su pertinencia para el lector medieval podía significar el potro de tormento. De tal suerte, la ética medieval era más compleja y más penetrante a través de la sociedad que la ética moderna -y en esto tiene razón Casserley-, pero esa influencia era más dañina que beneficiosa para la valoración de la persona humana. Esta era tal persona sólo dentro del sistema teológico, pero no en virtud de ser lo que era, y dentro de ese sistema un accidente podía cambiar a la persona de criatura de Dios a criatura del Diablo, con todas las terribles consecuencias que esto significaba. 
Gilman ${ }^{71}$ hace un alegato en favor de la objetividad moral en el sentido de la autocrítica y el desasimiento, y la distingue de lo correcto. Uno puede ser moralmente objetivo y sin embargo no estar en lo correcto. Terrell 72 subraya la objetividad y el carácter singular de las reglas morales. Al tomar decisiones morales, debemos esforzarnos por encontrar "razones que sean servibles a cualquier persona, sean ,cuales fueren sus inclinaciones personales... Una decisión ética peculiar, me parece, es cualquiera que se base en una razón que sea peculiarmente ética, y la alegación importante de la teoría ética objetivista es que hay tales razones, y, por tanto, decisiones particularmente éticas". El problema es sólo cuáles son esas razones. ${ }^{73}$ Negley ${ }^{74}$ argumenta en favor de la objetividad epistemológica. Los datos fundamentales de la experiencia moral han sido considerados erróneamente como condiciones subjetivas del sentir, únicas y privadas, incomunicables y, por tanto, no descriptibles en ningún lenguaje concebible. De tal suerte, la ética, debido a la observación defectuosa de su asunto, se ha hecho impotente para comunicar y se ha convertido, por torcimiento, en un ejercicio de epistemología. Por otra parte, como sostiene Allers, ${ }^{75}$ la índole privada y la unicidad de un asunto no implican necesariamente falta de comunicación en la teoría que trata dicho asunto. La experiencia del color es única y privada, pero no ha sido un estorbo para los físicos en el desarrollo de la espectroscopia. Aun si los valores son el tipo de experiencias que los emotivistas y los intuicionistas sostienen que son, podría desarrollarse una ciencia elaborada objetiva de la axiología.

Gellner ${ }^{76}$ profundiza más en la lógica de las razones éticas, empleando un tipo tradicional de lógica. El análisis de Oxford es inadecuado, pues sus conclusiones no pueden ser menos accidentales que su material, que es el lenguaje ordinario. " $\mathrm{El}$ análisis de la palabra alemana 'Schimmel' es 'caballo' y 'blanco', pero no es necesario que un idioma contenga tal palabra; el inglés, ciertamente, no la contiene. Algunos 'análisis de la ética' hacen que la respuesta parezca similarmente accidental. Pero esto simplemente no llevará a ninguna parte, pues la pregunta concernierite al análisis correcto de las afirmaciones éticas es ética ella misma; con lo cual quiero decir que, cuando hacemos la pregunta, lo que deseamos saber no es cómo usan las

71 "Objectivity in Conduct", Philosophy, 29, págs. 308-320 (1952).

72 "What You Will, or the Limits of Analysis", Philosophical Studies, 3, págs. 39.38 (1952).

73 Cf. Baier, "Proving a Moral Judgment", Philosophical Studies, 4, pág. 33 (1953), y Mayo, "Commitments and Reasons", Mind, 64, págs. 342-360 (1955) para otros exámenes del paralelo entre las razones éticas y teóricas.

74 "The Failure of Communication in Ethics", Symbols and Values: An Initial Stıdy, Bryson, L. et al., ed., Nueva York, 1954 .

75 "The Failure of Communication in Ethics" (Discussion), symbols and Values: An Initial Study, Bryson, L. et al., ed., Nueva York, 1954 .

76 "Ethics and Logic", Proc. Arist. Soc., 55, págs. 157-158 (1954-1955). 
afirmaciones éticas los habitantes de Huddersfield o de Bongo Bongo, sino cómo deben usarlas." Cuando las personas obran, están preparadas para dar razones de sus actos. Estas razones tienen una forma lógica; son juicios universales o singulares, de estos últimos si se hace referencia a alguna persona única como motivo del acto, como en el amor. Así, pues, hay dos, y sólo dos, clases lógicas de justificaciones de la acción, aquellas que emplean descripciones y constituyen así reglas abiertas (tipos U), y aquellas que contienen nombres lógicamente propios y de tal suerte no son abiertas (tipos E). Las teorías éticas se han construido alrededor de esta distinción, al efecto de que debemos obrar de tal manera que nuestras posibles justificaciones sean de uno u otro tipo. El primer tipo de ética (tipos U) es el Esencialismo kantiano, el segundo- (tipo E) es el Existencialismo. Ambas éticas son operantes, pero ambas son inadecuadas. El problema es: con base en qué criterio, externo a ambas, podría uno elegir entre ellas. Puesto que ambas son tipos de lógica, el criterio debe ser una lógica abarcadora, lo cual es una consecuencia del argumento de Gellner que éste no extrae.

La axiología formal es esta lógica abarcadora; ella define el valor intrínseco similar al tipo E de Gellner, y el valor extrínseco y sistemático similar a su tipo U. El valor moral, siendo intrínseco, es del tipo E.77 Esta conclusión se opone a la de Hare, para quien las valoraciones morales son del tipo U:78 Esto se debe no tanto a ceguera moral cuanto a falta de distinción lógica. Para Hare, no hay diferencia lógica entre un juicio acerca de buenos cronómetros y un juicio acerca de buenos hombres; ambos recomiendan. La vaga naturaleza categorial de su definición de lo bueno, como recomendar, no le permite analizar la bondad lógicamente en valor extrínseco y valor intrínseco, y, por tanto, desarrollar las lógicas correspondientes a estas dos clases de valor. Su ética es, pues, inarticulada; y su intuición no lo ayuda a superar la deficiencia de su falta de articulación. Su explicación para nuestra impresión usual de la mayor importancia de los juicios morales es tan inconvincente como superficial: que somos hombres y no cronómetros. ${ }^{79}$ Esta explicación se basa en la premisa de que lo que más nos concierne nos parece más valioso; pero no se da la conexión lógica entre concernencia y recomendación. La "explicación", pues, tiene el típico carácter ad hoc de los intentos analíticos, en oposición al carácter necesario de las soluciones sintéticas.

Tales soluciones, como hemos visto, las rechaza en principio la escuela semi-cognoscitivista de Oxford. Esta, como había señalado Hall, sustituye la Razón práctica kantiana con razones pragmáticas. Pone así un cuasi-naturalismo en lugar del no-naturalismo de Kant y no ofrece ninguna solución para el actual estancamiento en la ética; "no ofrece ninguna vía media entre

77 Véase La estructura del valor, del autor, págs. 307 sigs., 313.

78 R. M. Hare, "Universability", Arist. Soc., vol. LV, págs. $295-312$ (1954-1955).

70 The Language of Morals, págs. 140 sigs. 
el naturalismo y el no-naturalismo". Ya hemos visto que esta vía media es posible sólo mediante la interpretación formal del no-naturalismo; no es tanto una vía media cuanto una supercarretera que pasa por encima de todos los problemas de la dicotomía: el procedimiento sintético en oposición al analítico, la construcción de un lenguaje de valor en un nivel lógico superior al lenguaje ordinario. La insistencia en el lenguaje ordinario no sólo produce inconsecuencias metodológicas como el argumento ad hoc que acabamos de mencionar, sino que conduce a una falacia lógica, la de confundir el contenido con el método, el uso y la mención del lenguaje de valor, falacia que Hall hace muy clara. El agente en la situación moral usa el lenguaje de valor, el filósofo del valor lo menciona. El filósofo del valor no es el agente del valor, ni a la inversa, el agente del valor es el filósofo del valor. Por tanto, si bien el lenguaje ordinario debe usarse en la situación moral, no es necesario usar - ni debe usarse, ciertamente - un lenguaje tal en el metalenguaje del filósofo moral que está tratando o mencionando el lenguaje ordinario. Esta situación invalida ampliamente el prejuicio de Oxford contra la definición. El lenguaje de la Escuela de Oxford es un metalenguaje pragmático, y el de la ética filosófica un lenguaje semántico. El filósofo de la ética no es, como filósofo, parte de la situación que examina. Hampshire, ${ }^{80}$ por ejemplo, supone que los contextos posibles del debate ético son dos: el del elogio o el reproche moral ex post facto y el de llegar a una decisión moral. Ambos, dice Hall, "son situaciones morales prácticas cotidianas, no son el contexto de la discusión filosófica". Son su asunto. ${ }^{81}$

Mientras Hall ataca el aspecto semi-cognoscitivista de "la escuela de la buena razón" —el carácter al por menor de sus "razones"-, Edel y Monro atacan su aspecto no-cognoscitivista. Edel ${ }^{82}$ hace el mismo planteamiento lógico que Hall: Debemos distinguir entre el acto de decidir y el contenido cognoscitivo de la decisión. Hart, 83 según Edel, confunde estas dos cosas del mismo modo que, según Hall, las confunden Toulmin y Hampshire: "Que el papel de la teoría judicial sea el de orientar la decisión no entraña necesariamente que sea menos teórica. (La motivación de control de la física no implica una referencia de control al analizar 'movimiento' o "energía'.)" 84 En la ética hay un componente teórico al igual que en la ciencia, y no es claro en modo alguno que "sea la característica distintiva de los juicios prác-

80 "Fallacies in Moral Philosophy", Mind, 58, págs. 466-482 (1949). En su libro Thought and Action, Nueva York, 1960, Hampshire establece una conexión entre clasificación y valoración similar a la de la axiología formal.

81 Lamentablemente, Hall pasa por alto esta distinción fundamental en su propia obra sobre el valor. Véase R. S. Hartman, "Value, Fact and Science", Philosophy of Science, XXV, págs. $97 \cdot 108$ (abril de 1958).

8 "Ethical Reasoning", Academic Freedom, Logic and Religion, White, M., ed., Filadelfia, 1953 .

83 "The Ascription of Responsabilities and Rights", op. cit.

84 Edel, op. cit., pág. 138. 
ticos el que éstos tengan una fuerza prescriptiva o cuasi-imperativa como parte de su significado", como dice Hampshire. "Los juicios morales pueden ser y han sido formulados de tal manera que el elemento prescriptivo es parte de los fenómenos designados. Un enfoque cognoscitivista, sea naturalista o no-naturalista, no puede ser acusado, por tanto, de dejar fuera la prescripción. En la teoría ética, creo yo, nos estamos acercando al punto en que reestableceremos como el contexto primario en el que uno recibe orientación aquel en el que uno aprende o llega a ver claramente. Pues es un hecho simple que cuando a los hombres se les ayuda a ver claramente cuáles serán las consecuencias de sus actos y qué querrán ellos en las condiciones subsecuentes, entonces ellos han recibido orientación." 85 Edel se halla todavia muy lejos de advertir que el componente teórico de la ética requiere elaboración formal, como lo requirió el de la ciencia, y que una vez se lleve a cabo esta elaboración, la acción moral debe desprenderse de ella como el método inherente en la ciencia misma. Pero Edel sí advierte cuando menos el componente teórico y su naturaleza lógica. El esfuerzo de la Escuela de Oxford para establecer una nueva "lógica", "para introducir nuevos modelos de validez en la teoría ética, se apoya, o bien en suposiciones aceptadas con demasiada premura de que los modelos establecidos no son aprovechables, o bien en un pesimismo prematuro respecto al desarrollo de las ciencias humanas, o bien en una concepción estrecha de lo práctico que ignora la eficiencia cabalmente práctica de la cognición y la reflexión". ${ }^{86}$ Lamentablemente, el propio Edel no lleva adelante esta comprensión metodológicamente y hace clara la naturaleza sintética del conocimiento científico y su consecuencia lógica del método. Así, pues, lo que él dice es analíticamente vago, pero no sintéticamente preciso ni fundado. Con todo, en tanto que la Escuela de Oxford va contra el método cientifico - en un empiricismo tan ingenuo que llega a falsificar la empresa del conocimiento-, Edel va con este método, en un empirismo que es lo bastante refinado como para indicar su suplemento formal. Por otra parte, este empirismo concuerda, hasta cierto punto, con la filosofía que critica. 87

La concepción ingenuamente empírica del conocimiento que sustenta la Escuela de Oxford es el blanco de la crítica de Monro. ${ }^{88}$ Este subraya la diferencia fundamental entre las situaciones morales y otras situaciones de decisión y muestra que el método axio-empírico de la Escuela de Oxford, basado en la ingenua analogía entre la ética y la ciencia empírica, se desploma. "No podemos, simplemente por medio del examen de la manera como

85 Op. cit., pág. $14^{\circ}$.

86 Op. cit., pág. 142.

87 Véanse también las obras de Edel, Ethical Judment, Glencoe, I1l., 1955, y Science and the Structure of Ethics, Chicago, 1961.

88 "Are Moral Problems Genuine?", Mind, 65, págs. 166-183 (1956). 
se comporta la gente o de las razones que ésta considera justificativas de su comportamiento, arribar al concepto de un modo [moral] de vida." Esto último consistiría "en principios que se conforman a ciertos criterios formales, a saber, principios que se siguen consecuentemente, que son universalmente aplicables... y mutuamente consecuentes". Tal concèpto, contrariamente a lo que dice Toulmin, "sí necesita justificación, puesto que ni es universalmente aceptado en la práctica ni universalmente defendido en teoría; y es posible usar las palabras 'bueno' y 'debe' sin implicar tal concepto. Tampoco podemos justificar este concepto recurriendo a la función de los principios morales, ya sea que interpretemos ésta en el sentido de hacerle posible al hombre que coopere o simplemente en el de hacer posible el aprender y enseñar hábitos". Monro tampoco va lo suficientemente lejos y no afirma que los principios en cuestión, para ser moralmente eficientes, deben formar un sistema sintético y no deben consistir en lugares comunes analíticos. Tampoco dice lo que es obvio: que la mejor manera de "justificar" el concepto de tal sistema sería crear el sistema.

Rickman ${ }^{89}$ no sólo coincide con Monro en cuanto a la necesidad de un sistema ético, sino que ataca la "tenaz renuencia a todo enfoque sistemático" de la Escuela de Oxford, que conduce al "análisis lingüístico difuso y fragmentario", "la discursividad tortuosa, la colección de anécdotas triviales y la mezcla fortuita de reflexiones lingüísticas, psicológicas y sociológicas que no conduce a ninguna conclusión clara". Lo que se requiere es un enfoque positivo y sistemático inserto dentro de la estructura de una teoría general del lenguaje. Resignarse a la irreductible variedad y complejidad de las afirmaciones morales "sólo puede conducir al oscurantismo". Si hablamos en todo caso de tales afirmaciones como una clase, debemos esperar que la clase tenga una connotación. La caracterización única de los principios morales la ha dado Kant. La de las afirmaciones morales ordinarias en situaciones concretas - el meollo de la cuestión- es el ser aplicaciones de un principio moral a situaciones concretas. En la medida en que estas afirmaciones se refieren a los principios, son directivas, justificatorias y emotivas. En la medida en que se refieren a estados de cosas - y aquí tenemos lo exactamente contrario de Hare- son descriptivas y pueden ser verdaderas o falsas. Esta teoría resuelve no sólo el problema de la caracterización única de los juicios morales, sino que también evita la confusión fundamental de los formalistas semi-cognoscitivistas, entre los propósitos con que se hacen las afirmaciones y las funciones lingüísticas de esas afirmaciones. Por otra parte, no advierte claramente la necesidad de principios sintéticos en oposición a los analíticos y la imposibilidad de aplicar realmente principios analíticos, tales como los de Kant. La aplicación a situaciones concretas presupone más bien un patrón relacio-

89 "Linguistic Analysis and Moral Statements", Philosophy, 29, págs. 122-13o (1954). 
nal que uno implicativo, y un patrón cuya precisión aumente con el alcance de su. aplicabilidad. Esto sólo es posible con patrones sintéticos; es imposible con patrones analíticos.

Rice ${ }^{90}$ se acerca más a los requisitos lógicos de una teoría moral, cuando menos en su crítica de la Escuela de Oxford, aunque no en la construcción de su propia teoría. El programa de Oxford, dice Rice, no puede cumplirse realmente. Parece iṇstarnos "a retroceder hasta Céfalo en la Repriblica: El significado de los conceptos de valor, tales como la Justicia, ha de exhibirse por medio de una colección de afirmaciones acerca de las clases de conducta que se sostiene son justas, tales como decir la verdad o pagar nuestras deudas".91 Pero cuando se trata de cumplir tal programa en detalle, se ven obligados, a fin de introducir algún tipo de racionalidad interna en el asunto, a ofrecer principios de un grado mayor de generalidad que el programa inicialmente concebido. Así, Toulmin iguala el significado de "correcto" con su fuerza no-cognoscitiva, que para él es "gerundiva", noción que no se define en ninguna parte. Sin embargo, cuando pasamos a analizar el término "correcto", Toulmin dice que damos razones de tipo fáctico o cognoscitivo, y las razones admisibles muestran, o bien que el acto concuerda con las costumbres y reglas aceptadas de una sociedad, o bien, cuando éstas son impugnadas, con lo que viene a ser una versión empobrecida del principio utilitario. El principio utilitario, pues, le sirve a Toulmin en la práctica, como ha demostrado Broad en su reseña del libro, ${ }^{92}$ como una definición del elemento cognoscitivo en el significado del término; ${ }^{93}$ y esto, como dice Monro, ${ }^{94}$ le da a Toulmin la objetividad tenazmente negada de un principio moral. "Es curioso — dice Rice-, que Toulmin excluya el concepto principal en el 'análisis' del término, y el que más se asemeja a una propiedad definitoria, de su 'significado'. Pues, ¿qué analiza el análisis si no es el significado? La suposición parece ser que sólo el factor no-cognoscitivo es digno de ser dignificado con el status del significado, y que los elementos cognoscitivos no son parte de éste. Toulmin, sin embargo, no defiende explícitamente en parte alguna semejante concepción restringuida del significado." 95

A pesar de su agudo análisis, Rice no se eleva, en su propia teoría ética, por encima de la posición semi-cognoscitivista. Aclara, sin embargo, algunos de sus términos, tales como "significado", y el principio utilitario que se encuentra en la base de los conceptos morales. De tal suerte, Rice se convierte en el principal exponente de una versión más racional de la Escuela

90 On the Knowledge of Good and Evil, Nueva York, 1955.

91 Rice, op. cit., pág. 81 .

92 "An Examination of the Place of Reason in Ethics, por S. E. Toulmin", Mind, 61, págs. 93-101 (1952).

93 Rice, op. cit,, págs. 81 sig.

94 “Are Moral Problems Genuine?", Mind, 65, págs. 166-183 (1956).

95 Rice, op. cit., pág. 82. 
de Oxford: nos da no razones "por menor" sino razones "por mayor"; pero ambas están alejadas de la Razón.

Lo que se necesita en el "callejón sin salida" de la ética actual es recapturar esa Razón que inspiró a los grandes filósofos, desde Platón hasta Leibniz, Descartes, Spinoza y Kant, y que se reintegró en las creaciones de los científicos del Renacimiento y de la llustración. Necesitamos, en una palabra, un movimiento de Ilustración en la títica y la Axiología. Tal movimiento presupone la critica de la razón axiológica; la crítica de filosofías iluminadas no por la luz de la Razón sino solamente por las llamas vacilantes de razones contextuales. 90

ROBERT S. HARTMAN

96 Véase el libro del autor de próxima aparición, Critica de la razón axiológica. 